\title{
ENSINO DA MATEMÁTICA E O USO DAS NOVAS TECNOLOGIAS: UMA ABORDAGEM INTERDISCIPLINAR
}

\author{
Ana Beatriz Afonso de Sousa, Universidade Federal de Campina Grande (UFCG) \\ 07bibisousa@gmail.com \\ Rozivânia Fernandes da Silva, Universidade Federal de Campina Grande (UFCG) \\ vannynha2704@gmail.com
}

Prof. Dr ${ }^{\mathrm{a}}$ Raimunda de Fátima Neves Coêlho, Universidade Federal de Campina Grande (UFCG)

\author{
raimunda.neves6@gmail.com
}

\begin{abstract}
RESUMO
O presente artigo pretende analisar o uso das novas tecnologias na aplicação de jogos educativos virtuais numa perspectiva interdisciplinar, tendo em vista a avaliação e utilização desses recursos de ensino na aprendizagem da Matemática, nas primeiras séries do ensino fundamental. $\mathrm{O}$ trabalho pautou-se nas propostas dos Parâmetros Curriculares Nacionais (PCNs) para o ensino da Matemática e nos referenciais teóricos da Educação Matemática, em que foram realizadas análises referentes as metodologias de ensino e seus resultados. Para tanto, foram apresentadas formas de inserção e aplicação de jogos no ensino da Matemática, fundamentados na interdisciplinaridade, tendo em vista contribuir para o processo de ensino/aprendizagem, por meio de atividades lúdicas em sala de aula.
\end{abstract}

PALAVRAS-CHAVES: jogos educativos virtuais; interdisciplinaridade; ensino da Matemática.

\section{THE USE OF NEW TECHNOLOGIES IN MATHEMATICS TEACHING: AN INTERDISCIPLINARY APPROACH}

\begin{abstract}
This article aims to analyze the use of new technologies in the application of educational games in an interdisciplinary perspective, in view of an evaluation and teaching didactic abilities of Mathematics in the first grades of elementary school. The work was based on the proposals of the National Curricular Parameters (PCNs) for the teaching of mathematics and in the theoretical references of Mathematics Education, in which analyzes were carried out regarding teaching methodologies and their results. There is no teaching of Mathematics, based on interdisciplinarity; In order to contribute to the teaching / learning process, through playful activities in the classroom.
\end{abstract}

KEYWORDS: virtual educational games; interdisciplinarity; teaching of Mathematics; 


\section{EL USO DE LAS NUEVAS TECNOLOGÍAS EN LA ENSEÑANZA DE LA MATEMÁTICA: UN ENFOQUE INTERDISCIPLINAR}

\section{RESUMEN}

El presente artículo pretende analizarel uso de lasnuevastecnologíasenlaaplicación de juegos educativos virtuales desde una perspectiva interdisciplinaria, con vistas a laevaluación y utilización de esos recursos de enseñanzaenelaprendizaje de las Matemáticas enlasprimeras series de laenseñanza fundamental. El trabajo se basóenlaspropuestas de losParámetros Curriculares Nacionales (PCNs) para laenseñanza de la Matemática y enlos referentes teóricos de laEducación Matemática, en que se realizaronanálisis referentes a lasmetodologías de enseñanza y sus resultados. Para ello, se presentaron formas de inserción y aplicación de losjuegosenlaenseñanza de lasMatemáticas, fundamentados enlainterdisciplinariedad, conelfin de contribuir al proceso de enseñanza / aprendizaje, a través de actividades lúdicas enel aula.

PALABRAS CLAVES: juegos educativos virtuales; Interdisciplinariedad; Enseñanza de las matemáticas;

\section{INTRODUÇÃO}

O conhecimento matemático foi construído historicamente pela humanidade, como forma de conhecer e organizar os espaços e as relações com a sociedade, vindo a tornar-se uma ciência que influencia na vida do ser humano.

A matemática acompanha a humanidade desde os primórdios, procurando ajudar o homem a resolver problemas, construir e estabelecer relações de quantidade entre objetos, além de estar inserida em todas as áreas de conhecimento e por isso não deve ser vista como ferramenta que auxilia na obtenção de resultados exatos, ou apenas na aplicação de fórmulas e regras.

Os métodos tradicionais, no ensino de matemática, utilizados pela maioria dos professores não estimulam o aprendizado das crianças, o que acaba causando impactos negativos ao longo de sua vida. O uso dos jogos tecnológicos tem sido uma ferramenta metodológica de grande importância na compreensão do ensino da matemática, com a intenção de proporcionar aos alunos uma construção mais interativa na aprendizagem, bem como o desenvolvimento de raciocínio nas crianças. 
Para utilização desses jogos buscou-se na interdisciplinaridade uma prática que propiciasse uma interconexão entre as diferentes áreas do conhecimento e a partir dessa preocupação, encontrou-se em Japiassu explicação quando, assim, diz:

\begin{abstract}
A interdisciplinaridade é um método de pesquisa e de ensino suscetível de fazer com que duas ou mais disciplinas interajam entre si, esta interação podendo ir da simples comunicação das idéias até a interação mútua dos conceitos, da epistemologia, da terminologia, da metodologia, dos procedimentos dos dados e da organização da pesquisa. (JAPIASSU, 1976, p. 136)
\end{abstract}

Como método de ensino é importante destacar a interdisciplinaridade, que tem como proposta estabelecer a conexão entre as áreas do conhecimento, proporcionando, ao aluno, acesso à informação e uma melhor concepção sobre a Matemática aplicada aos demais campos do saber e para isto, é necessário ao professor trabalhar com informações reais e atuais.

As atividades de matemática devem ser pensadas como forma de facilitar a aprendizagem dos alunos, para isso as metodologias utilizadas devem buscar atender as dificuldades e necessidades e dessa forma, com o uso dos jogos na perspectiva da interdisciplinaridade tem-se observado cada vez mais a presença das novas tecnologias e do acesso a informação, como meio de proporcionar as crianças uma aprendizagem prazerosa e significativa, estimulando a vontade de aprender.

É de grande importância o desempenho e responsabilidade do professor no planejamento da utilização desses recursos, uma vez que ele será o mediador para que as ferramentas sejam eficazes no processo de construção do conhecimento matemático.

Diante da necessidade de buscar recursos para se alcançar resultados eficazes na educação é que objetivou-se analisar a inserção da tecnologia, por meio de jogos, buscando na interdisciplinaridade meios de contribuição para aprendizagem da matemática na sala de aula, reconhecendo a importância do planejamento para alcançar melhores resultados.

\title{
1. A FORMAÇÃO DO CONHECIMENTO MATEMÁTICO PELA CRIANÇA
}


É de grande responsabilidade do professor o planejamento para o desenvolvimento das atividades a serem realizadas na aula, com isso, é necessária a busca por formas de aplicar os jogos tecnológicos para que a aprendizagem da matemática seja satisfatória e os alunos consigam construir o conhecimento matemático. No texto: Agranionih e Smaniotto (2002 apud SELVA, 2009, p.2) o jogo matemático é "uma atividade lúdica e educativa, intencionalmente planejada, com objetivos claros, sujeita a regras construídas coletivamente, que oportuniza a interação com os conhecimentos e os conceitos matemáticos [...]".

Diante dos conhecimentos matemáticos que precisam ser trabalhados, o professor de matemática do ensino fundamental precisa considerar a quantidade de alunos em salas de aula, as realidades e as culturas diferenciadas, para que com isso possam integrar e trabalhar os conteúdos e também a socialização dos mesmo no ambiente escolar. É possível observar, segundo Vigotsky, que:

[...] as crianças formam estruturas mentais pelo uso de instrumentos e sinais, a brincadeira a criação de situações imaginárias surge da tensão do indivíduo e a sociedade. O lúdico liberta a criança das amarras da realidade, ou seja, é muito importante ter recursos para que as crianças desenvolvam de forma agradável e prazerosa a sua aprendizagem. (VIGOTSKY, 1989, p.84)

Sendo assim, é possível configurar o ensino de modo a tornar-se mais interessante aos alunos, influenciando por meio dos jogos a vontade de brincar que, consequentemente, propicia a aprendizagem e o interesse.

\section{OS RECURSOS TECNOLÓGICOS A FAVOR DA APRENDIZAGEM}

Nos Parâmetros Curriculares Nacionais encontram-se algumas orientações para o uso das tecnologias, em suas diferentes formas, estas são responsáveis por constituírem um dos principais agentes de transformação da sociedade, pelas modificações que exercem nos meios de produção e por suas consequências no cotidiano das pessoas. O uso desses recursos traz significativas contribuições para se pensar no processo de ensino e aprendizagem de Matemática, à medida que relaciona a importância do cálculo mecânico e da simples manipulação simbólica, uma vez que por meio do computador como ferramenta pedagógica, essas atividades e cálculos possam ser realizados de modo mais rápido, eficiente e desafiador. 
Embora nem todas as escolas possuam computadores que estejam disponíveis para a maioria dos alunos, grande parte já está integrada na utilização desses recursos como ferramenta educacional e podem ser utilizadas nas aulas com várias finalidades, a saber: como fonte de informação; poderoso recurso para alimentar o processo de ensino e aprendizagem; como auxílio no processo de construção de conhecimento; como meio para desenvolver autonomia pelo uso de softwares que facilitam aprendizagem, principalmente, de matemática; que possibilitem pensar, refletir e criar soluções e como ferramenta para realizar determinadas atividades.

Portanto, todas essas atividades podem ser um grande aliado para o desenvolvimento cognitivo dos alunos, principalmente, quando os trabalhos individuais e em grupo propõem uma adaptação para ritmos de aprendizagens diferenciados. O uso do jogo dispõe dessa facilidade por ser adaptável a cada dificuldade e pode ser inserido de acordo com as necessidades e possibilidades do aluno. Neste sentido, é que os jogos matemáticos virtuais como os disponíveis no Escola Games, Smartkids, Racha Cuca e tantos outros sites de jogos educativos podem ser facilitadores de aprendizagem, pois, é possível ao aluno ultrapassar as dificuldades aprendendo, assim, a lidar com elas e tornar-se apto a solucionar possíveis problemas.

Conforme os PCN'S (1998) uma vantagem relevante nos jogos é o desafio, que faz com que os alunos sintam mais interesse e prazer pela disciplina. Logo, os jogos são peças fundamentais para que a sociedade tenha indivíduos capazes de buscar soluções, enfrentarem desafios, serem criativos e com estratégias para se tornarem pessoas críticas.

\section{A INTERDISCIPLINARIDADE COMO MÉTODO DE ENSINO DA MATEMÁTICA}

A interdisciplinaridade é um método de ensino de grande importância na construção e apropriação do conhecimento, e deve ser utilizado como forma de estabelecer uma relação entre campos distintos do saber. Segundo os PCNs do Ensino Fundamental:

A interdisciplinaridade questiona a segmentação entre os diferentes campos de conhecimento produzida por uma abordagem que não leva em conta a inter-relação e a influência entre eles questiona a visão compartimentada (disciplinar) da realidade sobre a qual a escola, tal como é conhecida, 
historicamente se constituiu. Refere-se, portanto, a uma relação entre disciplinas. (BRASIL, 1997, p.31)

Em se tratando da Matemática, a interdisciplinaridade é fundamental, pois é através dessa perspectiva que se torna mais dinâmico o processo de relação entre os conteúdos. Assim, foi desenvolvida uma oficina matemática em uma turma do $3^{\circ}$ ano de Ensino Fundamental, para se observar se esse tipo de método facilitava a aprendizagem matemática e sua relação com demais disciplinas.

Essa oficina teve como objetivo avaliar aprendizagem dos alunos na perspectiva interdisciplinar, a partir da inserção dos jogos virtuais nesse processo de aprendizagem do ensino de matemática. A maior dificuldade encontrada tratou-se de crianças que não diferenciavam as quatro operações matemáticas. Nesse intuito foram elaboradas atividades lúdicas na oficina que proporcionaram as crianças vivenciarem na prática o conhecimento matemático do seu cotidiano, como por exemplo: a elaboração de um minimercado onde os mesmos usassem cédulas para que eles pudessem exercitar as quatros operações nesse contexto de compras e vendas.

Desse modo, cada situação precisaria usar as quatro operações e demais conhecimentos que não eram específicos de matemática, mas, das demais áreas. Percebeu-se que quando eles vivenciavam determinada situação, aprendiam o conteúdo de forma mais satisfatória, e no segundo momento inseriram-se os jogos digitais para que assimilassem o conhecimento trabalhado. $\mathrm{O}$ site escola games proporcionou atividades que envolveram os alunos facilitando a aquisição de seus conhecimentos matemáticos. Diante dessa experiência foi possível perceber que houve um interesse maior em participar das atividades e uma significativa aprendizagem para os participantes.

\section{CONSIDERAÇÕES FINAIS}

Coma oficina de leituras e observações feitas acerca dos jogos virtuais matemáticos foi possível concluir a importância da inserção dessa metodologia, como forma de facilitar a aprendizagem do conhecimento lógico matemático pelos alunos, diante da forma divertida e prazerosa trabalhada. No uso dos jogos é preciso considerar que a aplicação e uso dos jogos 
virtuais devem ter uma intencionalidade, pois se as atividades não forem bem elaboradas pode-se não alcançar os objetivos de aprendizagem.

Concluiu-se que o uso da oficina e os jogos de uma forma interessante e prazerosa propõe uma forma divertida de ensino-aprendizagem, fazendo com que os alunos aprendam a ser criativos e a solucionar problemas de forma clara e objetiva, sendo assim satisfatória para seus conhecimentos tecnológicos e lógico matemático. De acordo com os PCN (1998, p.46) “o que se propõe hoje é que o ensino de Matemática possa aproveitar ao máximo os recursos tecnológicos, tanto pela sua receptividade social como para melhorar a linguagem expressiva e comunicativa dos alunos".

Logo, destacou-se a relevância da utilização do método de ensino trabalhado, isto é, a interdisciplinaridade na utilização de jogos virtuais para o ensino da matemática com crianças do ensino fundamental.

\section{REFERÊNCIAS BIBLIOGRÁFICAS}

BRASIL, Ministério da educação - Secretaria de educação fundamental - PCN’S

Parâmetros curriculares nacionais. Brasília: MEC/SEF, 1998.

JAPIASSU, H. Interdisciplinaridade e patologia do saber. Rio de Janeiro, Imago, 1976.

SELVA, K.R, GT 01. Educação Matemática nos Anos Iniciais e Ensino Fundamental: O jogo matemático como recurso para a construção do conhecimento. In: X EGEM X ENCONTRO GAÚCHO DE EDUCAÇÃO MATEMÁTICA COMUNICAÇÃO CIENTÍFICA, 2009, Ijuí. Anais... Ijuí: UNIJUÍ, 2009.

VYGOTSKY, L.S. Pensamento e Linguagem. São Paulo: Martins Fontes, 1989. 